\title{
Potential risk factors for onset of severe neck and shoulder discomfort (Katakori) in urban Japanese workers
}

\author{
Takayuki SAWADA ${ }^{1,2 *}$, Ko MATSUDAIRA ${ }^{3}$, Yumiko MUTO ${ }^{1}$, \\ Tadashi KOGA ${ }^{1,4}$ and Masaya TAKAHASHI ${ }^{5}$
}

\author{
${ }^{1}$ Clinical Study Support, Inc., Japan \\ ${ }^{2}$ Department of Public Health, Aichi Medical University, Japan \\ ${ }^{3}$ Department of Medical Research and Management for Musculoskeletal Pain, 22nd Century Medical and \\ Research Center, Faculty of Medicine, the University of Tokyo, Japan \\ ${ }^{4} \mathrm{CPC}$ Clinical Trial Hospital, Medipolis Medical Research Institute, Japan \\ ${ }^{5}$ National Institute of Occupational Safety and Health, Japan
}

Received July 28, 2015 and accepted December 18, 2015

Published online in J-STAGE January 30, 2016

\begin{abstract}
Katakori is a Japanese word, and there is no clear English translation. Katakori consists of two terms, Kata means neck and shoulder, kori means stiffness. Consequently, Katakori is defined as neck and shoulder discomfort or dull pain. Katakori is a major somatic complaint and has a large impact on workers. To examine the association between onset of severe Katakori and potential risk factors in Japanese workers, a prospective cohort study, entitled "Cultural and Psychosocial Influence on Disability (CUPID)", was conducted. Self-administered questionnaires were distributed twice: at baseline and 1 year after baseline. Logistic regression was used to explore the risk factors of onset of severe Katakori. Of those 1,398, the incidence of severe Katakori onset after 1 year was 3.0\% (42 workers). Being female (adjusted odds ratio: 2.39, 95\% confidence interval: 1.18-4.86), short sleep duration (adjusted odds ratio: $2.86,95 \%$ confidence interval: $1.20-6.82$ ) and depressed mood with some issues at work (adjusted odds ratio: $3.11,95 \%$ confidence interval: $1.38-7.03$ ) were significantly associated with onset of severe Katakori. Psychosocial factors as well as gender difference were associated with onset of severe Katakori. We suggest that mental health support at the workplace is important to prevent severe Katakori.
\end{abstract}

Key words: Katakori, Prospective study, Risk factors, Japanese workers, Psychosocial factors

\section{Introduction}

Katakori is a Japanese word, and there is no clear English translation. Katakori consists of two terms, Kata means shoulder and kori means stiffness. Consequently, Katakori is defined as discomfort or dull pain caused by muscle stiff-

*To whom correspondence should be addressed.

E-mail: takayuki_sawada@jp-css.com

(C2016 National Institute of Occupational Safety and Health ness around the back of the head and through the shoulders and/or shoulder blades ${ }^{1)}$. Katakori is usually classified as one of the cervico-omo-brachial syndrome. The symptoms of Katakori are considered to be close to "neck pain" or "chronic nonspecific neck pain" as expressed in the references $^{2-4)}$.

Katakori is classified into primary Katakori (essential Katakori) which does not identify any causable disease (organic disorder) and secondary Katakori (symptomatic Katakori) which is caused by disease. Examples of disease 
which can be the cause of secondary Katakori include cervical spine disease, glenohumeral joint disease, cardiovascular disease, pulmonary disease, eye fatigue, temporomandibular arthrosis, and menopausal syndrome ${ }^{5,6}$.

The prevalence of Katakori is $6.1 \%$ among males and $13.1 \%$ among females in $\mathrm{Japan}^{7}$, therefore Katakori is a major somatic complaint which is comparable to low back pain and has a large impact on people including workers with subjective symptoms, however, its pathogenesis is still unclear. Furthermore, the association between Katakori and potential risk factors has not been properly assessed in prospective epidemiological research.

There have been reports of several risk factors associated with Katakori: such being female ${ }^{6-9}$, using a Visual Display Terminal $(\mathrm{VDT})^{6}$ ) and mental health ${ }^{9,10)}$. These factors have been identified based on the results of cross-sectional studies.

A prospective cohort study, entitled "Cultural and Psychosocial Influence on Disability (CUPID)", was conducted to explore further the impact of cultural and psychosocial influences on musculoskeletal symptoms and associated disability ${ }^{11,12)}$. A cross-sectional analysis of baseline data shows that being female and depressed mood have been associated with severe Katakori in urban Japanese workers ${ }^{8)}$. In this study, using one year of followup data, we conducted a continued analysis to examine the association between onset of severe Katakori and potential risk factors in urban Japanese workers. To our knowledge, this was the first longitudinal study assessing the potential risk factors for onset of severe Katakori. In this study, we especially focused on severe Katakori since Katakori is a common symptom among Japanese workers.

\section{Subjects and Methods}

Data from a 1-year prospective cohort of the CUPID study were used for this analysis. The CUPID study is an international joint research project, which has involved 18 countries. In Japan, ethical approval for the study was obtained from the ethics committees of the University of Tokyo Hospital and review board of the Japan Labour Health and Welfare Organization. All participants provided written informed consent.

The workers around Tokyo including office workers, sales and marketing personnel, transportation workers, and nurses were recruited.

The board of each participating organization was asked to distribute a self-administrated questionnaire along with a cover letter from the study administration office to their

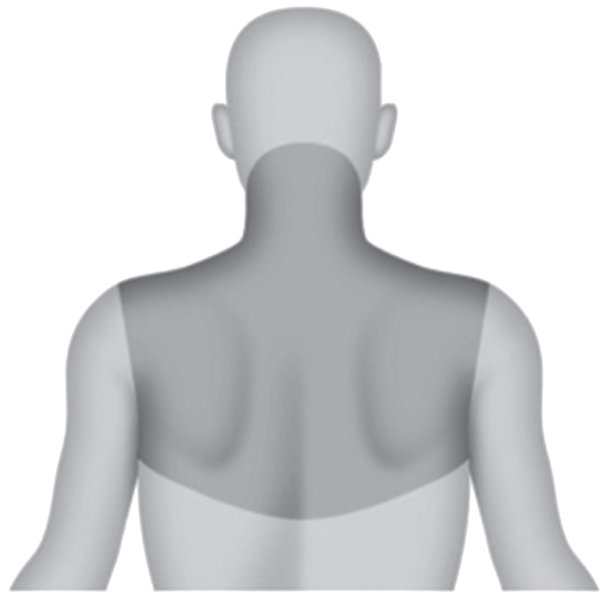

Fig. 1. Diagram showing pain area for Katakori.

workers. Responders were asked to return their completed questionnaires by mail and to provide their names and mailing addresses for direct correspondence from the study administration office for 1-year follow-up purposes.

The original questionnaire used in the CUPID study was translated into Japanese with some newly designed questions for Japanese workers regarding Katakori. The translation equivalence with the original questionnaire was checked through independent back-translation into English. For the participants, the pain area of Katakori was defined as the back of the head and through the shoulders and/or shoulder blades (Fig. 1). At baseline, respondents were asked about the frequency and severity of Katakori they had experienced during the previous month. The frequency of Katakori was assessed on a 6-point scale (1, always; 2, almost always; 3 , often; 4, sometimes; 5 , seldom; 6, never); the severity of Katakori was measured on an 11-point numerical rating scale (NRS) ranging from 0 (no Katakori) to 10 (severe Katakori). At follow-up, the frequency of Katakori was assessed using three duration periods (1-6 days, $1-2$ weeks, or $\geq 2$ weeks) and the severity of Katakori was measured by NRS.

In addition, the baseline questionnaire assessed individual characteristics (i.e., age, gender, age at the last educational status, body mass index (BMI), hours of sleep, marital status, regular exercise, smoking habits, visual fatigue, dental therapy, dental bite, and outpatient with articular and spine symptoms), ergonomic work demands (period of current service, working hours per week, VDT use, finger repetition, lifting, driving, standing, and work shift), and psychosocial factors (job satisfaction, job control, inadequate break time at work, worksite support, interpersonal stress at work, and experience of depressed mood with an issue at 
work). Variables were categorized by the same methods previously used in the CUPID study for Katakori associa$\operatorname{tion}^{8)}$. Age was categorized as $<30$ years, 30-39 years, $40-49$ years or $\geq 50$ years. BMI was calculated by height and body weight recorded in a questionnaire; BMI $\geq 25$ was defined as obesity. Age at the last educational status was categorized as $\leq 19$ years or $>19$ years; low education was defined as $\leq 19$ years. Regular exercise was defined as physical exercise performed more than twice a week for 20 minutes or longer during the previous 12 months. Short sleep duration was defined as an average of $<5$ hours. Low experience in current job was defined as $<1$ year of current service. Sixty hours of working hours per week was defined as high work demand. VDT was defined as work using the computer display for $\geq 4$ hours per shift. Lifting was defined as a work to lift or move $\geq 25 \mathrm{~kg}$ (object or person) by hand. Driving was defined as $\geq 4$ hours of car or truck driving per shift. Standing was defined as $\geq 4$ hours standing per shift. Work shift was defined as irregular work shift such as night shift. To assess the level of job satisfaction, responders were asked, "Considering everything, how satisfied are you with your work?" Answers were the following four choices: "Very satisfied", "Satisfied", "Not well satisfied" and "Not satisfied at all". Low job satisfaction was defined as an answer of "Not well satisfied" or "Not satisfied at all". To assess the level of job control, responders were asked, "How much control do you have in your work?" These items had four response options: often, sometimes, seldom, and never/almost never. Low job control was defined as an answer of "seldom" or "never/almost never". To assess the level of worksite support, responders were asked, "When you have difficulties in your work, how often do you get help and support from your colleagues or supervisor/manager?" This item had five response options: often, sometimes, seldom, never, and not applicable. Low worksite support was defined as an answer of "seldom" or "never" for worksite support. Depressed mood with some issues at work was defined as experience of that in past 12 months.

The follow-up questionnaire was distributed 1 year after the baseline assessment, and the second questionnaire was sent only to the participants who returned the first one with their written consent of participating. Therefore, those who did not return a questionnaire did not participate in the study any longer.

The outcome of interest was onset of severe Katakori during the 1-year follow-up period. In this study, severe Katakori was defined as frequency more than 2 weeks in the previous month and as severity with NRS more than 7

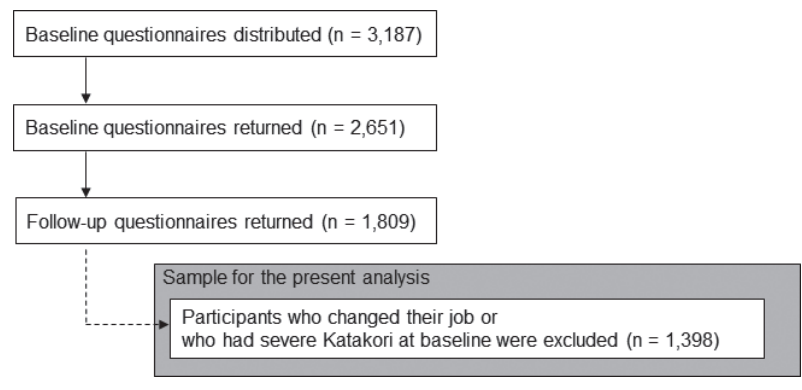

Fig. 2. Flowchart of the sample selection.

points at the follow-up. Incidence was calculated for the participants who reported no severe Katakori at baseline, as we defined severe Katakori as frequency more than often and as severity with NRS more than 7 points during the previous month. Participants were excluded from the analysis if they had changed their job.

For statistical analysis, in addition to compiling descriptive statistics, logistic regression was used to explore the associations between risk factors and onset of severe Katakori. Results of logistic regression analyses were summarized by odds ratios (ORs) and the respective $95 \%$ confidence intervals (CIs). For the assessment of potential risk factors, crude ORs were initially estimated. Factors with p-values $<0.1$ were considered to be potential risk factors. We conducted a multivariate logistic regression analysis using potential risk factors in the model and then using a stepwise selection method in which terms were retained if they reached the 0.05 level of significance. All statistical tests were two-tailed, and conducted with a significance level of 0.05. The software package SAS Release 9.3 (SAS Institute Inc., Cary, NC) was used for statistical analyses.

\section{Results}

The baseline questionnaire was distributed to 3,187 participants and was completed by 2,651 participants. The following year, 1,809 participants successfully completed and returned the follow-up questionnaire, thereby yielding a follow-up rate of $68.2 \%$.

Participants $(n=411)$ were excluded from the analysis if they had severe Katakori at baseline $(n=330)$ or those who changed their job $(n=81)$. Thus, a total of 1,398 participants were included in the present analysis (Fig. 2).

Mean (SD: standard deviation) age was 37.3 (10.0) years, of which 1,398 of $73.8 \%$ of participants were male. Jobs were nurses $(21 \%)$, office workers $(15 \%)$, sales and marketing personnel $(21 \%)$ and transportation operators (43\%). [Table 1] The incidence of onset of severe Katakori 
Table 1. Characteristics of responders

\begin{tabular}{lccc}
\hline \multicolumn{1}{c}{ Characteristics } & Severe Katakori & Non-Severe Katakori & Total \\
\hline N (\%) & $42(3.0 \%)$ & $1,356(97.0 \%)$ & 1,398 \\
Gender & & & \\
$\quad$ Male, n (\%) & $21(2.0 \%)$ & $1,011(98.0 \%)$ & $1,032(73.8 \%)$ \\
$\quad$ Female, n (\%) & $21(5.7 \%)$ & $345(94.2 \%)$ & $366(26.2 \%)$ \\
Age, mean (SD) & $37.1(9.0)$ & $37.3(10.0)$ & $37.3(10.0)$ \\
Job type & & & \\
$\quad$ Transportation operative & $15(2.5 \%)$ & $585(97.5 \%)$ & $600(43.0 \%)$ \\
$\quad$ Sales/marketing personnel & $5(1.7 \%)$ & $289(98.3 \%)$ & $294(21.0 \%)$ \\
$\quad$ Nurse & $16(5.4 \%)$ & $278(94.6 \%)$ & $294(21.0 \%)$ \\
$\quad$ Office workers & $6(2.8 \%)$ & $204(96.7 \%)$ & $211(15.1 \%)$ \\
\hline
\end{tabular}

Table 2. Crude odds ratios of the risk factors for onset of severe Katakori

\begin{tabular}{|c|c|c|c|}
\hline Risk factors & $\%$ & $\begin{array}{l}\text { Crude odds ratio } \\
\quad(95 \% \mathrm{CI})\end{array}$ & $p$ value \\
\hline \multicolumn{4}{|l|}{ Gender } \\
\hline Male & 73.8 & 1.00 & \\
\hline Female & 26.2 & $2.92(1.58-5.42)$ & 0.001 \\
\hline \multicolumn{4}{|l|}{ Age (yr) } \\
\hline$<30$ & 25.5 & 1.00 & \\
\hline $30-39$ & 37.3 & $1.79(0.74-4.33)$ & 0.197 \\
\hline $40-49$ & 22.6 & $1.64(0.62-4.35)$ & 0.324 \\
\hline$\geq 50$ & 14.6 & $1.51(0.50-4.57)$ & 0.462 \\
\hline \multicolumn{4}{|c|}{ Outpatient with articular and spine } \\
\hline No & 97.2 & 1.00 & \\
\hline Yes & 2.8 & $0.82(0.11-6.14)$ & 0.850 \\
\hline \multicolumn{4}{|c|}{ Outpatient with dental therapy } \\
\hline No & 92.7 & 1.00 & \\
\hline Yes & 7.3 & $1.35(0.47-3.87)$ & 0.537 \\
\hline \multicolumn{4}{|l|}{ Wrong dental bite } \\
\hline No & 83.8 & 1.00 & \\
\hline Yes & 16.2 & $1.76(0.85-3.65)$ & 0.130 \\
\hline \multicolumn{4}{|l|}{ Visual fatigue } \\
\hline No & 56.3 & 1.00 & \\
\hline Yes & 43.7 & $2.20(1.15-4.21)$ & 0.017 \\
\hline \multicolumn{4}{|l|}{ BMI } \\
\hline$<25 \mathrm{~kg} / \mathrm{m}^{2}$ & 84.0 & 1.00 & \\
\hline$\geq 25 \mathrm{~kg} / \mathrm{m}^{2}$ & 16.0 & $1.50(0.71-3.19)$ & 0.291 \\
\hline \multicolumn{4}{|l|}{ Current smoking } \\
\hline No & 56.4 & 1.00 & \\
\hline Yew & 43.6 & $1.44(0.78-2.66)$ & 0.245 \\
\hline \multicolumn{4}{|c|}{ Age at last educational status (yr) } \\
\hline$\geq 20$ & 62.4 & 1.00 & \\
\hline$<19$ & 37.6 & $0.66(0.33-1.29)$ & 0.221 \\
\hline \multicolumn{4}{|l|}{ Regular exercise } \\
\hline Yes & 20.2 & 1.00 & \\
\hline No & 79.8 & $1.50(0.62-3.60)$ & 0.367 \\
\hline \multicolumn{4}{|l|}{ Marital status } \\
\hline Married & 56.4 & 1.00 & \\
\hline Not married & 43.3 & $1.20(0.65-2.21)$ & 0.568 \\
\hline \multicolumn{4}{|l|}{ Sleep duration } \\
\hline$\geq 5 \mathrm{~h}$ & 56.4 & 1.00 & \\
\hline$<5 \mathrm{~h}$ & 43.3 & $2.75(1.24-6.10)$ & 0.013 \\
\hline \multicolumn{4}{|l|}{ Experience in current job } \\
\hline$\geq 1 \mathrm{yr}$ & 90.6 & 1.00 & \\
\hline$<1 \mathrm{yr}$ & 9.4 & $1.32(0.51-3.42)$ & 0.569 \\
\hline
\end{tabular}

\begin{tabular}{|c|c|c|c|}
\hline Risk factors & $\%$ & $\begin{array}{c}\text { Crude odds ratio } \\
(95 \% \mathrm{CI})\end{array}$ & $p$ value \\
\hline \multicolumn{4}{|l|}{ Working hours per week } \\
\hline Low & 59.2 & 1.00 & \\
\hline High & 40.8 & $0.89(0.47-1.67)$ & 0.715 \\
\hline \multicolumn{4}{|c|}{ Inadequate break time at work } \\
\hline Not inadequate & 45.6 & 1.00 & \\
\hline Inadequate & 54.4 & $3.16(1.50-6.66)$ & 0.003 \\
\hline \multicolumn{4}{|l|}{ VDT } \\
\hline Not VDT & 75.3 & 1.00 & \\
\hline VDT & 24.7 & $1.23(0.62-2.42)$ & 0.557 \\
\hline \multicolumn{4}{|l|}{ Finger repetition } \\
\hline No & 77.7 & 1.00 & \\
\hline Yes & 22.3 & $1.09(0.53-2.25)$ & 0.811 \\
\hline \multicolumn{4}{|l|}{ Lifting } \\
\hline No & 47.4 & 1.00 & \\
\hline Yes & 52.6 & $1.09(0.59-2.03)$ & 0.777 \\
\hline \multicolumn{4}{|l|}{ Driving } \\
\hline No & 64.5 & 1.00 & \\
\hline Yes & 35.5 & $1.01(0.53-1.91)$ & 0.980 \\
\hline \multicolumn{4}{|l|}{ Standing } \\
\hline No & 43.1 & 1.00 & \\
\hline Yes & 56.9 & $1.93(0.98-3.80)$ & 0.058 \\
\hline \multicolumn{4}{|l|}{ Work shift } \\
\hline Regular shift & 60.8 & 1.00 & \\
\hline Irregular shift & 39.2 & $1.73(0.94-3.21)$ & 0.058 \\
\hline \multicolumn{4}{|l|}{ Job satisfaction } \\
\hline Satisfied & 43.4 & 1.00 & \\
\hline Not satisfied & 56.6 & $1.38(0.74-2.57)$ & 0.310 \\
\hline \multicolumn{4}{|l|}{ Job control } \\
\hline Controlled & 46.4 & 1.00 & \\
\hline Not controlled & 53.6 & $0.64(0.35-1.19)$ & 0.528 \\
\hline \multicolumn{4}{|l|}{ Worksite support } \\
\hline Supported & 91.3 & 1.00 & \\
\hline Not supported & 8.7 & $1.15(0.40-3.27)$ & 0.800 \\
\hline \multicolumn{4}{|l|}{ Interpersonal stress at work } \\
\hline Not stressed & 51.2 & 1.00 & \\
\hline Stressed & 48.8 & $1.93(1.02-3.66)$ & 0.045 \\
\hline \multicolumn{4}{|c|}{ Depressed mood with some issue at work } \\
\hline Not feeling depressed & 50.0 & 1.00 & \\
\hline Depressed & 50.0 & $4.15(1.89-9.07)$ & $<0.001$ \\
\hline
\end{tabular}

CI: confidence interval. 
Table 3. Adjusted odds ratios of risk factors which were significant for onset of severe Katakori

\begin{tabular}{llc}
\hline \multicolumn{1}{c}{ Risk factor } & $\begin{array}{c}\text { Adjusted odds ratio } \\
(95 \% \mathrm{CI})\end{array}$ & $p$ value \\
\hline Gender & & \\
$\quad$ Male & 1.00 & \\
$\quad$ Female & $2.39(1.18-4.86)$ & 0.016 \\
Sleep duration & & \\
$\quad \geq 5 \mathrm{~h}$ & 1.00 & \\
$<5 \mathrm{~h}$ & $2.86(1.20-6.82)$ & 0.018 \\
Depressed mood with some issue at work & & \\
$\quad$ Not feeling depressed & 1.00 & \\
$\quad$ Depressed & $3.11(1.38-7.03)$ & 0.006 \\
\hline
\end{tabular}

CI: confidence interval.

Adjusted by gender, sleep duration and experience of depressed mood with some issue at work

in the follow-up period was 3.0\% (42 workers), with mean (SD) age of $37.1(9.0)$ years. Of those, $50 \%$ were males.

To assess the effect of the selected drop-out, the baseline characteristics of patients who were followed up $(n=1,809)$ and those who dropped-out $(\mathrm{n}=842)$ are calculated. The mean (SD) age was 37.3 (10.0) years and $33.6(8.5)$ years, respectively, and the majority were men in both groups $(66.0 \%$ vs $57.7 \%)$. The prevalence of severe Katakori was $18.8 \%$ and $21.2 \%$, respectively.

Crude odds ratios of baseline factors for onset of severe Katakori are shown in Table 2. The factors potentially relating to onset of severe Katakori were gender, visual fatigue, sleep duration, inadequate break time, standing, work shift, interpersonal stress and depressed mood with some issues at work. In psychosocial factors, depressed mood with some issues at work was only included, instead of interpersonal stress at work, because of its strong correlation ( $\rho=$ 0.4137, $p<0.0001)$. The crude odds ratio of depressed mood with some issues at work was higher than the interpersonal stress at work, thus the higher factor was selected. Because 77\% (281/366) of females were nurses, and $87 \%$ $(255 / 294)$ of nurses were defined as irregular work shift, the correlation between female and irregular work shift was strong $(\rho=0.3422, p<0.0001)$. Previous studies reported that Katakori was associated with females, so "female" was included in multivariate logistic regression analysis.

In the multivariate logistic regression analysis, these six factors were entered into the model. As a result, three potential risk factors were selected (Table 3 ).

A supplemental analysis was conducted to examine a combined impact of gender and nurses because $77 \%$ (281/366) were female nurses. We performed multivariate logistic regression analysis with the main three effects, nurse and interaction of gender and nurse. The adjusted odds ratios of main effects were similar to the main analysis, and the nurse effect as well as the interaction were not statistically significant. Based on these results, we propose three potential risk factors: gender, short sleep duration, and depressed mood with some issues at work which might associate with severe Katakori.

\section{Discussion}

To examine the association between onset of severe Katakori and potential risk factors, we conducted analyses using data from the CUPID study among urban workers in Japan. Although the incidence was small, severe Katakori occurred during the 1-year follow-up in some workers who had no or mild symptoms at baseline. A series of analyses showed gender, low sleep or depressed mood with some issues at work as important potential risk factors.

In our results, females showed higher odds (adjusted odds ratio $=2.18$ ) as a potential risk factor for onset of severe Katakori. According to the supplemental analysis, being female is potential risk factor of Katakori as it eliminates the possibility of nurses to affect the main result of this study. Based on these results, this study suggests the association of gender as a potential risk factor of severe Katakori. This finding is similar to those published previously $^{6,8,9)}$. We speculate this trend may be attributable to gender differences in muscle strength. Estrogen may also be involved in the pathogenesis of Katakori, although there is no scientific evidence for this assertion. Further studies will be required to explain the reason for gender differences in the manifestation of Katakori.

Being in a depressed frame of mind with some issues at work showed 3.1 times more increased risk of severe Katakori than those who are not. Previous cross-sectional studies suggest the association of Katakori and work stress, which was classified as a psychosocial factor ${ }^{1,6)}$. Krantz et $a l$. have reported that emotional stress and psychologically stressful tasks are associated with increased electrographic activity in the trapezius muscle ${ }^{13)}$, and Hallman et al. have reported that autonomic imbalance is associated with neck shoulder pain, the Japanese definition of Katakori ${ }^{14)}$. We suggest that psychosocial stress can progress to sympathetic and muscle stress, which may lead to the onset of Katakori.

In the present study, we found short sleep duration to be a potential risk factor. Mulligan et al. reported that nocturnal pain was associated with sleep quality, sleep duration, and habitual sleep efficiency in patients with shoulder dis- 
orders $^{15)}$. Short sleep duration might delay a daily recovery of tissue damage and cause the onset of severe Katakori. In order to ensure an adequate sleep duration, individuals should be responsible in attaining the required sleep duration, and support can be provided by encouraging a nonstressful work environment. In the present study, we had assessed sleep duration only. Further studies are required to explore any association between Katakori and the quality of sleep, including insomnia and other sleep disorders.

Factors identified as potential risk factors in the present study can be explained by Eriksen's hypothesis that headdown and neck flexion positions and/or psychological stress increase the intracellular nitric oxide/oxygen ratio through sympathetic nerve activity, resulting in inhibition of cytochrome oxidase; and then, lactate production would follow activating nociceptive fibers ${ }^{16)}$.

There were some limitations in this study. First, the generalizability of the findings may be limited. The majority of participants were male, and therefore a broad range of Japanese occupations was not represented. The study cohort was not a representative sample of the entire spectrum of Japanese workers in urban areas. Being female was one of the potential risk factors of Katakori although no interaction effects of gender and nurse were found in our supplemental analysis. However, the majority of females in this study were nurses, and the sample size included in the supplemental analysis may not have been sufficient. Therefore, our results need to be interpreted with care. Second, misclassification, to some extent, is inevitable. Information might be subjective in the decision of Katakori or sicknesses and missing value cannot be avoided due to the nature of a self-assessment survey. Third, drop-out may introduce bias into the data analysis due to the low followup rate of this study, although we considered that the baseline characteristics of both the follow-up group and the drop-out group seemed to be similar. Fourth, this study may not cover some unquestioned items which were not involved in the questionnaire. For example, some peculiar characteristics of Japanese may not be addressed by the original CUPID questionnaire regarding stress at work. Also, there were some items which were not involved in the original CUPID questionnaire as follows: disabilities of the arm, shoulder and hand questionnaire scores correlated significantly with depressive symptoms, catastrophic thinking, kinesiophobia, and pain anxiety ${ }^{17}$. The aforementioned behavioral items may need to be included as additional potential risk factors of severe Katakori. At last, a more complicated analysis model might be suitable for further assessment to discover other potential risk factors, instead of the logistic regression models assessed for the present analysis.

In conclusion, being female, short sleep duration and depressed mood with some issues at work were associated with onset of severe Katakori. We suggest that mental health support including the lack of sleep is important to prevent severe Katakori, especially for females.

\section{Acknowledgements}

We thank Dr. David Coggon and Keith T. Palmer for organizing and leading the CUPID study; CUPID collaborators for all their dedications, and Dr. Noriko Yoshimura for data collection in Japan. The study was a part of clinical research projects conducted by the Japan Labour Health and Welfare Organization.

\section{References}

1) Yabuki S (2007) Pathogenesis of the Neck-shoulder Stiffness (Katakori). Rinsho Seikei Geka (Clinical Orthopedic Surgery) 42, 413-7 (in Japanese).

2) Ijmker S, Huysmans MA, van der Beek AJ, Knol DL, van Mechelen W, Bongers PM, Blatter BM (2011) Softwarerecorded and self-reported duration of computer use in relation to the onset of severe arm-wrist-hand pain and neckshoulder pain. Occup Environ Med 68, 502-9.

3) McLean SM, May S, Klaber-Moffett J, Sharp DM, Gardiner E (2010) Risk factors for the onset of non-specific neck pain: a systematic review. J Epidemiol Community Health 64, $565-72$.

4) Kadi F, Waling K, Ahlgren C, Sundelin G, Holmner S, Butler-Browne GS, Thornell LE (1998) Pathological mechanisms implicated in localized female trapezius myalgia. Pain 78, 191-6.

5) Takagishi K, Hoshino Y, Ide J, Sugihara T, Hata Y, Sano H, Hamada J, Yabuki S, Mochiduki Y, Suzuki K, Yanagawa T, Tamai K, Ogawa K, Atsuta Y, Shinozaki T (2008) A project study for Katakori, 2004-2006 (commentary). Nihon Seikeigeka Gakkai Zasshi (The Journal of the Japanese Orthopaedic Association) 82, 901-11 (in Japanese).

6) Fujii $T$, Matsudaira $K$, Noma $K$, Isizuka A, Yamada $K$, Arisaka M, Higashikawa A (2012) Objective Measurement of Neck-shoulder Discomfort and Analysis of Associated Factors. Rinsho Seikei Geka (Clinical Orthopaedic Surgery) 47, 619-24 (in Japanese).

7) Japan Ministry of Health, Labour and Welfare. Comprehensive Survey of Living Conditions 2013. http:/www.mhlw. go.jp/toukei/saikin/hw/k-tyosa/k-tyosa13/dl/04.pdf. (In Japanese) Accessed Jul 16, 2015.

8) Fujii $T$, Matsudaira K, Yoshimura N, Hirai M, Tanaka S (2013) Associations between neck and shoulder discomfort (Katakori) and job demand, job control, and worksite sup- 
port. Mod Rheumatol 23, 1198-204.

9) Kimura T, Tsuda Y, Uchida S, Eboshida A (2006) Association of perceived stress and stiff neck/shoulder with health status: multiple regression models by gender. Hiroshima $\mathrm{J}$ Med Sci 55, 101-7.

10) Iizuka $Y$, Shinozaki T, Kobayashi $T$, Tsutsumi S, Osawa $T$, Ara T, Iizuka H, Takagishi K (2012) Characteristics of neck and shoulder pain (called katakori in Japanese) among members of the nursing staff. J Orthop Sci 17, 46-50.

11) Coggon D, Ntani G, Palmer KT, Felli VE, Harari R, Barrero LH, Felknor SA, Gimeno D, Cattrell A, Serra C, Bonzini M, Solidaki E, Merisalu E, Habib RR, Sadeghian F, Kadir M, Warnakulasuriya SS, Matsudaira K, Nyantumbu B, Sim MR, Harcombe H, Cox K, Marziale MH, Sarquis LM, Harari F, Freire R, Harari N, Monroy MV, Quintana LA, Rojas M, Salazar Vega EJ, Harris EC, Vargas-Prada S, Martinez JM, Delclos G, Benavides FG, Carugno M, Ferrario MM, Pesatori AC, Chatzi L, Bitsios P, Kogevinas M, Oha K, Sirk T, Sadeghian A, Peiris-John RJ, Sathiakumar N, Wickremasinghe AR, Yoshimura N, Kielkowski D, Kelsall HL, Hoe VC, Urquhart DM, Derrett S, McBride D, Gray A (2012) The CUPID (Cultural and Psychosocial Influences on Disability) study: methods of data collection and characteristics of study sample. PLoS One 7, e39820.

12) Matsudaira K, Palmer KT, Reading I, Hirai M, Yoshimura N, Coggon D (2011) Prevalence and correlates of regional pain and associated disability in Japanese workers. Occup Environ Med 68, 191-6.

13) Krantz G, Forsman M, Lundberg U (2004) Consistency in physiological stress responses and electromyographic activity during induced stress exposure in women and men. Integr Physiol Behav Sci 39, 105-18.

14) Hallman DM, Ekman AH, Lyskov E (2014) Changes in physical activity and heart rate variability in chronic neckshoulder pain: monitoring during work and leisure time. Int Arch Occup Environ Health 87, 735-44.

15) Mulligan EP, Brunette M, Shirley Z, Khazzam M (2015) Sleep quality and nocturnal pain in patients with shoulder disorders. J Shoulder Elbow Surg, pii: S10582746(15)00086-5. doi:10.1016/j.jse.2015.02.013.

16) Eriksen W (2004) Linking work factors to neck myalgia: the nitric oxide/oxygen ratio hypothesis. Med Hypotheses 62, $721-6$.

17) Das De S, Vranceanu AM, Ring DC (2013) Contribution of kinesophobia and catastrophic thinking to upper-extremityspecific disability. J Bone Joint Surg Am 95, 76-81. 